\title{
Building An Effective Team: The Influence Of Leadership Style On Modes Of Collaboration
}

\author{
Dr. Sandra Ingram and Dr. Amne Parker \\ Department of Electrical and Computer Engineering \\ University of Manitoba
}

En raison de l'importance croissante des projets d'équipe dans le domaine du génie, autant dans la salle de classe qu'au lieu de travail, il est nécessaire de cherche à mieux comprendre la nature du travail d'équipe en et à identifier les facteurs aptes à stimuler un succès d'équipe. Cet article se concentre sur ce qui constitue la collaboration efficace et est responsable du succès d'un style de leadership. Plus spécifiquement, il compare les styles individuels de leadership de trois étudiants participant à trois équipes. Même les résultats présentés ici font parties d'une plus grande étude qualitative concernant l'influence du gendre des participants sur le fonctionnement des équipes de travail des étudiants-ingénieurs engagés dans des projets de collaboration, cet article s'en tient à la présentation des données relatives aux styles de leadership. L'article conclut qu'une seule des trois équipes, en grande partie en raison de l'influence positive de son chef et de son propre style collégial, a su produire un document de plus haute qualité en exhibant les qualités nécessaires à une collaboration efficaces, telles quidentifiées par Allen et ses collégues (1987), soit: la présence à la fois d'interactions équilibrées, d'un modèle consensuel de prise de décision, et d'un partage efficace des responsabilités.

Because of the increasing importance of team based projects in both the engineering classroom and the workplace, there is a need to understand the nature of team work itself and to identify those factors that will foster a team's success. This paper will focus on what constitutes effective collaboration and a successful leadership style; specifically, it will compare the individual leadership styles of three students on three teams. While the findings discussed here are part of a larger qualitative study that looks at the influence of gender on engineering student teams who are engaged in a collaborative project, this paper will present only the data that relate to team leadership styles. The paper concludes that, largely because of its leader's positive influence and its 
own collegial style, only one team produced a higher quality document at the same time as it exhibited the attributes identified by Allen et al. (1987) as critical to effective collaboration: balanced interactions combined with consensual decision-making and shared responsibility.

We gratefully acknowledge the financial support of the Engineering Information Foundation, New York, which allowed the study to be conducted. We also acknowledge the support of Manitoba Hydro, Manitoba Telecom Services, the Faculty of Engineering, and the Department of Electrical and Computer Engineering, University of Manitoba.

This research conforms to the regulations of the university and has been approved by the Research and Ethics Committee, Faculty of Education, University of Manitoba.

A version of this article was first presented at the annual conference of the Canadian Association of Teachers of Technical Writing, as part of the Congress of the Social Sciences and Humanities (Quebec City, Quebec, May 2001).

\section{Introduction}

The literature on team behavior in organizational settings identifies a lack of leadership as the primary reason why teams fail to develop properly or improve their productivity (Stewart and Manz, 1995). Indeed, recent theories on leadership indicate that effective teamwork may be related to two important functions. First, a team must be organized to accomplish its tasks. Secondly, it must "stick together" and function well as a social unit. Similarly, in a classroom setting, research suggests that this same relationship between team leadership and team outcomes holds equally true (MacIver and Epstein, 1991). Thus, for students who are collaborating for the purpose of producing a single shared document, the success of their written effort may, in part, be linked back to the form or style of leadership in place.

\section{Research Approach}

The findings presented here are part of a larger qualitative study exploring the influence of gender on collaboration, a study conducted in the Faculty of Engineering at a major Canadian university. Because it is team-based, the technical communi- 
cation course offered by this faculty served as the specific site for the study of team dynamics. For this study, we defined collaboration as a series of activities leading to a shared product, in this case the final written report for the course. More specifically, using Allen et al.'s definition (1987), collaboration can be seen as a process that involves "producing a shared document, engaging in substantive interaction about the document, and sharing decision-making power and responsibility for it" (p. 70).

From 1997 to 1999, the researcher (Ingram) followed three teams of students as they made their way through the planning, organizing, and writing up of their final written report for the course. Using the methods of observation, semi-structured interviews, and document analysis, she examined both the characteristics that contribute to an effective group dynamic as well as how gender forces operate on a team dynamic. Audio-taped recordings of all in-class and out-of-class meetings enabled the researcher to fully analyze the interactional data. The professor for the course (Parker), in addition to evaluating each individual's performance in the group, also observed the teams within the classroom, and her observations were instrumental in supplementing the study's observational component. These methods, including the data analysis procedures, have been described in greater detail elsewhere (Ingram \& Parker, Gender and Collaboration, 2002b).

The research framework was situated theoretically within both macro and micro sociological traditions; an explanatory model was then developed from a synthesis of these traditions to make sense of the resulting data. This model concludes that gender is a complex force, shaped both by larger, structural relations of power and by smaller, interactional occurrences. This complexity can be seen on the two teams whose organizational structure was predominantly male (Ingram \& Parker, "Influence of Gender on Collaborative projects," $2002 \mathrm{c}$ ), where there is evidence of more traditional feminine and masculine interactional behaviors as well as glimpses of the culture of engineering described by Mcllwee and Robinson (1992). Conversely, on the all-female team, there is no evidence of interactional behavior linked to traditional notions of femininity. Thus, the findings cast doubt on the existence of strictly male and female communication styles while at the same time drawing attention to the importance of analyzing behavior as it is situationally produced (Ingram and Parker, "Gender and Modes of Collaboration," 2002a; Herrick, 1999). The study concludes that, while having some impact, gender has less influence on a team's overall dynamic than do factors such as leadership style.

Leadership is important to a team's success (or failure) precisely because it is in the interactions between team members that a team articulates its goals, decides who will do what and when, and develops a direction for the project. In its broadest sense, leadership "occurs when particular individuals exert influence upon others" (Johns, 
1996, p. 333). A leadership style may, however, have either a positive or a negative influence on a team. To be a positive influence on a team, an effective leadership style must include those skills that facilitate the two functions of team organization and social unity. Thus, an effective leader will be one who helps to build team cohesion and then works hard to maintain it; a leader will be concerned with more subtle social and emotional influences such as reducing tension and maintaining morale (Johns, 1996). At the same time, an effective leader is able to envision how to accomplish tasks related to the project and achieve team goals through planning and organizing; an effective leader should also be willing both to delegate tasks and to set boundaries.

What follows is a discussion of the three teams : the Resource Management and Aerospace teams, who had greater difficulty in establishing successful collaboration, and the MIT team (a name that was a combination of the Mechanical, Industrial, and Transportation topics, and one the team devised themselves), who were more effective in their collaborative efforts, and produced a higher quality report for the course. The leadership styles of their respective leaders, Carol, Denise, and Todd, are presented in this context and are seen to be a pivotal influence in the collaborative outcomes.

\section{Results}

In addition to their imbalanced patterns of interaction, their delayed decisionmaking, and their failure to fulfill their responsibilities, the Resource Management team and the Aerospace team showed little cohesion throughout the term; as well, they exhibited poor leadership in all the roles to be assigned for the course (Appendix 1). One reason they experienced difficulty in collaborating effectively can be traced to their collaborative style; they did not combine balanced interactions with consensual decision-making and shared responsibility. Nowhere was this more apparent than in the role of coordinating editor, a particularly crucial role since it involved organizing the team and keeping it on track. As leaders, both Carol and Denise became in time negative influences who did little to promote team unity or a sense of ownership in the final product.

\section{Carol}

At 20, Carol was older than her colleagues, since she had transferred into engineering after two years in a chemistry program. She based her decision to switch faculties largely on the job prospects available to graduate engineers. In doing so, she was still able to have a science-based career, something she was eager to pursue. While in university, Carol returned to her small home town on the weekends and worked at 
her family's grocery store. She also worked part-time during the week at the copy centre located on campus. Independent and very organized, Carol was able to juggle a full course load and two part-time jobs.

From the very beginning, Carol was an active member of the Resource Management team and showed herself able to take charge. After several meetings and much dithering about where and when they could meet, Carol became the team's coordinating editor more by default than by choice, assuming the role largely because she was already leading the discussions and no one else seemed to want the responsibility. Yet, while she was quite conscientious about doing her own work and was a capable manager of her own time (having come to rely on a day planner to keep her on track), she was far less effectual in managing the team's time or its activities. For example, she did not devise either a team meeting schedule or agendas, nor did she put any internal deadlines in place. Consequently, everything to do with the project-from discussions on its possible focus, to writing and revising the drafts-remained haphazard and last-minute.

She also couldn't seem to instill in her three team-mates any sense of responsibility. Often, they were only too eager to finish the task at hand, regardless of the quality of the product. Nowhere was Carol's ineffectual leadership more evident, however, than in her inability to set boundaries, both for herself and for others. This inability to delegate and to insist that the others do their jobs meant that she did most of the team assignments herself, including the final written report. Rather than create tension within the group, Carol chose to do the work of the entire team (Morgan, 1994, p.215). Nor did she seek the professor's guidance in dealing with a lazy, uncommitted team.

But more damaging to the group was the team's failure to read the course handbook prepared by the professor. In the short term, this failure meant they were often unprepared for class and for meetings, but, in the long term, it also led to mistaken assumptions about the requirements for the final written report. By far the most costly was their assumption that the report could be single-spaced and the visuals appended. Because they were unaware of the required length and layout of their report, at the last minute they had to make substantial cuts and revisions to their final report, and this adversely affected the analysis they were able to do. In any event, the report lacked a technical focus, becoming merely a narrative about different energy options.

In the final analysis, Carol's style of leadership meant that she did not provide sufficient direction that would allow her team-mates to fulfill their responsibilities. They remained to the end a loose collection of individuals who happened to work together rather than a team committed to common goals and mutually accountable to each other. Instead, the Resource Management team can be described simply as a 
group of people with a common assignment (Katzenbach and Smith, 1993, p. 45), and Carol's accommodating nature finally undermined whatever cohesiveness the team had. Over the course of the project, all but Carol had less and less commitment, and, ultimately, less and less sense of ownership in the final product. Carol's willingness to do everything-from choosing graphics to writing and revising, to printing and photocopying-meant that she had abdicated her role as a leader who should build social unity and structure the team for success, the very cornerstones of an effective leadership style.

\section{Denise}

For her part, Denise also made no particular effort to provide the kind of leadership that would be conducive to a well-functioning team. While Carol struggled to avoid the perception that she was (in her words) "bitchy or bossy," and along the way lost sight of what a good leader should be, Denise seemed to relish her self-appointed role of team boss. Her team was comprised of four young women: Tanya, Andrea, Reena, and Denise herself. Denise was clearly the most outspoken and expressive member of her team, her hands always gesturing and her face animated. But this apparent openness and charisma soon degenerated into a bluntness aimed at humiliating her team-mates, Tanya and Reena. Indeed, her persistent bullying reached the point where the team was doomed to failure, splintering at last into two sub-groups at odds with each other.

At the time of the study, Denise was 19 and had just entered her second year of the program with a declared major in mechanical engineering. She developed her interest in the profession in her last year of high school where she had the chance to take part in a national pilot program on women and technology. Part of the program involved a summer job placement where she worked with an engineer conducting residential flood inspections. Andrea was also a bright young woman who had won several entrance scholarships to the faculty. The other two team-mates were Tanya and Reena. Slightly older than her counterparts, Tanya had lived in Canada for only six years. Her eventual alliance with Reena, the youngest member of the group, was almost inevitable since Reena, too, had lived in the country for a short time, having arrived only a year earlier. Pitted against Denise's more aggressive approach to team work, these more timid young women were soon overwhelmed.

Indeed, very early on in the project, this team had the appearance of a fractured unit, Reena non-committal in her attitude toward the project, the course, and the team, and Tanya absent for most of the planning sessions held at the beginning of the term. Clearly, Andrea and Denise of necessity had to form an alliance in order to get things done and begin the project, though it quickly became apparent that it was 
Denise who took the most active role in directing others. Yet, while she behaved more like the team's coordinating editor, she officially assumed the role of graphics editor, preferring instead to oversee the visuals the team would use in both the oral and the written reports.

From the beginning, she was a dominant force on the team. Since Reena soon abandoned the coordinating editor's job, and the team subsequently decided not to reassign the role, Denise soon became increasingly domineering and ultimately quite intimidating for the other team members. Partly because the team lacked a strong coordinating editor to help build and maintain cohesion, and partly because the project tasks and team responsibilities were so ill-defined, Denise began to dictate the focus of the project and to tell the other members what exactly they were to do. Additionally, there was no written record of any of their deliberations, which meant that, if Denise said something was so, then it was. And Andrea, of course, was always there to side with Denise and reinforce her insistence that things be done a certain way. In the end, most decisions were made exclusively by the Denise-Andrea alliance, who would later inform the other two members what decisions had been reached and what tasks had now been assigned to them. As a result, decision-making was left to only half the members of the group, and the other half were left to flounder.

Denise, then, for all her charisma, was less a leader than she was "bossy," the very thing that Carol sought to avoid. Paying far less attention to the human or social side of leadership, such as consensus-building or inclusivity, she intimidated the other members of her team, demanding, for example, that they repeat instructions back to her as though they were inattentive children rather than colleagues. Nor was there any consultation on any of the decisions she made about the project. The end result was a team rife with conflict, distrust, and tension; the collaborative process collapsed, and the final report itself was a messy hodge-podge of disconnected ideas on a universal code for space technology.

\section{A Profile of a Successful Leadership Style: Todd}

In contrast to these two ineffectual leaders, Todd, the coordinating editor of the MIT team, exemplified the two important qualities of leadership-building team cohesion, and organizing the team so it could accomplish its tasks. At 20, he was two years older than his team-mates, and had recently made the decision to enter engineering after completing one year of basic science in which he received a full scholarship. Skilled in both the artistic and technical areas, Todd struggled with the possibility of pursuing a degree in Fine Arts. He already had four years experience creating and selling artwork of various kinds, and, at one point, had three employees and 
several volunteers working for him. Although his business was never formally registered, Todd had accumulated experience in such areas as dealing with internal and external deadlines, managing staff, and organizing meetings and agendas.

- Paying Attention to the Task:

Todd's task-oriented approach was evident from the earliest team meetings, something that Winter, Neal, and Waner report on in their study of mixed-gender groups and the group's perception of leadership (2001, p. 47). For every meeting the team held, both in and out of class, Todd produced an itemized agenda and circulated a copy to all team members. Although the professor encourages the use of agendas for team meetings, and even provides samples to guide students through the first few classes, many teams never adopt the strategy. The MIT team, however, was different. Todd's agendas contained the standard opening and closing items, such as a "review of the last meeting" and "other business." But he also paid particular attention to summarizing the meeting to ensure that all team members agreed with the major decisions and actions that had been taken. If the team's attention span wandered too far from the item under consideration, Todd was able to refocus the discussion by referring back to the agenda.

However, what drove the body of his agendas was a focus on deadlines and the importance of having various course requirements completed on time, as stipulated in the course handbook. So, Todd was not just concerned that the team meet external deadlines imposed by the professor; increasingly, his attention turned to the importance of setting internal deadlines so that the team would be ahead of crucial due dates. Todd's agenda of September 22, 1997 provides an early indication of this focus, in which Todd circulated to team members a breakdown of proposed internal deadlines related to the team proposal.

As the term progressed and due dates related to the final oral report and final written report loomed nearer, he produced and distributed a calendar for the month of November, containing proposed internal due dates. Todd's agendas also drew attention to the need for contingency plans should they arise, as shown in Figure 1, a copy of an agenda from the team's tenth meeting. It contains the standard concern for due dates, but it also includes an item on how to deal with the recent withdrawal from the course by the team's technical editor, Dwayne.

The ability to produce such itemized agendas that were deadline-driven required that Todd read the handbook, or, as coordinating editor, at least be familiar with its basic components, as he admitted in his personal interview with the researcher: 


\section{REVIEW LAST MEETING}

2. SINCE LAST MEETING

- Dwayne has left group

- Abstracts

- Information gathered for written report

\section{TECHNICAL EDITOR'S POSITION?}

\section{OUTLINE}

- Changes?

\section{DATES OF CONCERN}

- Oct 17, Individual drafts of the abstract assignment are due.

- Oct 20, Individual drafts of the final written report are due.

- Oct 22, Confidential review due.

- Oct 28, Team abstract due.

6. OTHER BUSINESS

7. ACTION STEPS

8. SUMMARY OF MEETING

9. ADJOURNMENT

\section{Figure 1: Agenda of October 14, 1997 (Meeting No. 10)}

Todd: I arrived at [the agenda] by looking at the handbook partly.... all I needed to know was when the deadline was.

Ingram: What clued you in to the idea of using agendas?

Todd: Well, they keep people on track.... I think the agenda just provided people with the general sense. Even if it was just subconscious, it just gave you a little bit of structure to your thinking - especially when I started putting the deadline reminders on it. [The team] really started tuning in: "Wow! That means I have to get my part done by then!"

Not only did Todd make extensive use of agendas, but also he was adept at the "language" of agendas. He typically used such phrases as "calling the meeting to order," "next item," "table this item," and "meeting adjourned," terms which further solidified the agenda structure for the team. The rest of the team found Todd's use of agendas to be very beneficial to their collaboration, as evidenced by what they said in 
their peer evaluations and the interviews conducted with them. For example, in her peer evaluation, Melissa referred to Todd's "excellent use of agendas which served to focus our attention and keep the meetings on topic."

Another distinctive feature of Todd's task-oriented approach to leadership was the emphasis he placed on setting boundaries, particularly in relation to workload. As coordinating editor, he played a central role in both the long-term and short-term planning of the collaborative project and, thus, in establishing the division of labor. However, in fine tuning the roles and responsibilities of team members, he was careful not to assume any additional tasks beyond his jurisdiction. While he always made himself available to the team should they require any assistance with their assigned roles, he had no difficulty-unlike Carol-in stipulating where his responsibilities ended. By the third meeting, for example, Todd already had a clear sense of each team member's role in the design and submission of the team proposal, including his own:

The binding is my responsibility, but the whole thing has to be typed up. It has to be typed up by Monday, which is what I've written down here. So Monday it should be typed, and the people who might be responsible for that would be Dwayne, Kevin and Melissa. You guys have to collaborate on trying to type it up. Basically, by Wednesday, we should know exactly what we're doing and we should start researching.

Similarly, with another course-related assignment, the case study assignment, Todd reminded the team that it was an individual responsibility, even though they were discussing it collectively as a way to brainstorm on the technical problem, criteria, and possible solutions.

We've got the case study due on Thursday, seven days from today. Does everyone know what they're doing for that?.... It's [an] individual [assignment], so don't expect the group to do it.

- Paying Attention to Human Relations:

Notwithstanding his firm expectations of the team, Todd was equally balanced in his concern for the social and emotional needs of his colleagues. His leadership style could best be described as participatory and consultative in that he relied heavily on input from others. For example, although as coordinating editor Todd was responsible for much of the planning and organization of the collaborative project, he looked to the team to ratify many of the procedural decisions he made. His "proposed" internal deadline schedule, referred to earlier, provides an early indication of his desire to achieve a consensual approach to decision-making. 
This approach was equally apparent in many of the technical discussions concerning the final written report. Initially, it was Todd's idea to research magnetic levitation systems (maglev) and explore their feasibility in Canadian climates. Although each team member brought forward their own ideas, soon the team became excited as the discussion began to revolve around the "maglev" concept. However, before proceeding further with the topic, Todd was careful to ensure that his idea was agreeable to all team members when he asked: "You guys like this one? You want to work on maglev?" His attempt to make certain that the entire team had unanimously accepted the topic should not be overlooked. As the Aerospace team exemplifies, not all team members are always given an opportunity to fully express themselves, and, instead, they have gone along with ideas that they did not support; doing so could result in months of agony for all parties involved.

Another part of Todd's leadership style encompassed the use of frequent "pulse checks" to see how all team members were able to cope, both from the technical and research point of view, with the various demands of the collaborative project. From time to time, particularly as the final due dates drew nearer, he would momentarily depart from the prescribed agenda to inquire about team members' feelings, and, if possible, resolve any confusion or doubt they were experiencing. Todd was also not afraid to admit to the team if he were having problems with understanding either technical material or course material detailing the requirements for written assignments. In addition, he made use of feedback and did not hesitate to compliment his colleagues on work well-done, as he did when he was reviewing the specifications for the team proposal before its submission:

Todd: Gantt chart done, illustrations.... other components.... recorder's notes... (To Melissa) You've done an excellent job; they're beautiful. And they're done, right?

Melissa: Yeah, but I have to spell check. I forgot about that. And you've seen my typing ability.

Todd: Anything else? I don't think so. We've done a lot. I think everybody's doing a good job.

The sensitivity and perceptiveness Todd showed towards his team-mates was equally evident in his patterns of non-verbal communication, as observed in several in-class meetings the team held. The team had adopted a unique style of communication, sitting in close proximity to each other, often huddled together, and gesturing in 
unison when meetings ended. Todd played a central role in this configuration as he initiated and directed many of the team's discussions. With a soft-spoken and gentle manner, he would show his attentiveness by leaning into the team and turning his body towards the team-mate he was addressing. Todd used direct patterns of eye contact, nodded his head, and often smiled warmly as he listened intently to team members' concerns. The team's preparations for their oral progress report exemplifies his style of communication. Moments before the team delivered its report to the class, he made use of the huddle technique to calm team members, particularly Melissa, who had earlier left the room to be ill. By gathering the team in a semi-circle at the front of the classroom and having a few words with them beforehand, Todd was able to coach them towards giving a moderately successful presentation.

In the interview conducted with him, Todd acknowledged the importance of being "tuned in" to patterns of non-verbal communication:

Melissa often was not included in some of the conversations, but I could tell when she had something to say, so then I would ask her, "Is there anything else?" Or I would just gesture, and then she would say something. You can always tell when somebody's got something to say, and you can kind of look at everyone a certain way. I don't know.... It's natural. I don't know how to explain it.

From this brief overview, it is evident that Todd's distinctive form of leadership had a substantial impact on the team's ability to organize itself effectively and function well as a social unit. The team's peer evaluations of Todd confirm this view. Here, the team indicated their respect for the particular leadership style Todd brought to the collaborative project. He was highly commended, not only for his organizational skills and consistent use of agendas, but also for his "professionalism" and "relaxed, confident approach." A brief analysis of the team's approach to interaction, decisionmaking, and responsibility-the three cornerstones of collaboration-will reveal further the extent to which strong leadership skills are connected to a successful collaborative effort.

\section{- Interaction:}

Before examining the various forms of interaction used by the MIT group as identified by Van Pelt and Gillam (1991), it is worth noting the structure in which these interactions took place as a means of further piecing together the components for effective collaboration. Both the MIT group and the Resource team had 14 in-class opportunities to meet throughout the term; the Aerospace team had 15 in-class meetings. However, the MIT group held an additional 12 meetings out of class, for a total 
of 26 meetings, twice the number of out-of-class meetings held by the Resource team, which held six such meetings, and four more out-of-class meetings than the Aerospace group, which held eight such meetings. The MIT group's out-of-class meetings were typically held in the classroom immediately after class ended. Not only did this venue provide the team with a quiet location and no distractions, but also it gave them the opportunity to incorporate into their planning process any developments that took place in class while these were still uppermost in their minds.

Other noteworthy features of the group's meeting structure were the frequency, length, and attendance associated with their meetings. Throughout the term, their out-of-class meetings were held often and at regular intervals, with a notable increase in the number of meetings as important deadlines drew nearer. The average length of these meetings was 30 minutes. Todd mentioned in the team interview that he took this time frame into consideration when planning meetings due to the limited attention span of most individuals.

The patterns of attendance and punctuality for individual team members were equally consistent. With the exception of one team member, Dwayne, who early on withdrew from the course, the level of dedication and commitment from the rest of the team remained high. There were only three absences on the part of David, the stylistic editor, and one absence on the part of Kevin, the graphics editor, during the entire 26 meetings. Neither Todd, the coordinating editor, nor Melissa, the recorder, missed a single team meeting. As their roles are primarily concerned with the smooth functioning of the team and its effective collaboration, this finding is of particular significance, for, without this level of commitment, the team may well have floundered just as the Resource Management and the Aerospace teams did.

In terms of the interactive style utilized by the MIT group, relatively equal attention was devoted to the categories of interaction identified by Van Pelt and Gillam (1991). The balanced manner in which the team managed its interactions may be seen as a significant factor in accounting for the successful team dynamic as well as the higher quality report that emerged. Once again, the use of a pre-set agenda, copied and circulated to all team members, was a central feature in contributing to a productive interactional style. The itemized topics to be discussed helped to reduce the opportunity for one form of talk to take up a disproportionate amount of meeting time.

Procedural talk was a regular feature of most meetings, simply due to the significant amount of coordination necessary in working on a collaborative project of this magnitude. Organizing the division of labor, arranging meeting times and locations, making provisions for the exchange of drafts, and planning practice sessions for oral presentations were just some of the procedural issues to be discussed. However, with the MIT group, none of these topics consumed an entire meeting. Todd's agendas 
were normally structured in such a way that procedural issues were dealt with towards the beginning of the meeting, leaving sufficient time for substantive, and, increasingly, writing issues to be discussed. Although the team referred in their interview to the importance of injecting humor into their discussions and going off-topic at times, the researcher was unable to find excerpts from their conversations in which social talk lasted more than a few minutes.

There were some meetings in which one form of talk, such as procedural, substantive, or writing talk, would predominate. However, there were other occasions in which all three forms of interaction were equally distributed. Figure 2 is a copy of the team's agenda for their 16th meeting that was held out of class. During this 45 minute session, attention was given to procedural items concerning the final written report, such as internal and external deadlines related to drafts, possible dates for their exchange and revision, as well as Todd's proposed calendar for the month of November.

In addition, there were other procedural items discussed concerning the final oral report, including the team's use of a multi-media approach to present it. Then, under the fifth item, "Draft discussion," a significant amount of time was devoted to writing talk, as team members reviewed drafts and critiqued them. But there was also substantive talk, in which the team clarified any remaining topic-related issues. In an excerpt taken from this meeting, both writing and substantive talk actually become fused at one point:

\section{Review Events}

2. O.P.R. Discussion

3. Deadline Reminder

- Nov 10 Individual drafts of final written report due

- Nov 18 Final written report due (15\%)

- Nov 19 Final oral reports begin (15\%)

4. Calendar

5. Draft Discussion

6. Other Business

7. Summary of Meeting

8. Adjournment

A:/agendas/Oct29 97

Figure 2: Agenda of October 29, 1997 (Meeting No. 16) 
Todd: I think it should be almost like, I don't know. I mean, we're just talking about the feasibility of it working in Canada.....Like, you might say it cannot be used to replace a bus system, because there are simply too many stops and starts, or something like that.

Kevin: Well, like, in a subway, stops and starts are....

Todd: But it could be used as a subway system.

Kevin: Okay, .... Of course, there's the harsh [climate] requirement in Canada, and then we're going to talk about our economic position. Does Canada have the economy to support the position? Does it have the need? Oh, this is in that section right?

Todd: Feasibility, yeah.

Kevin: Do we have the need for it? Do we have the economy for it?.... Do we have the right-I guess geographic commuter routes for it?

Todd: I've got about three pages. And then I've got....I've got three pages done on mine. And I've got three diagrams. Um, my problem so far is-I want to learn a little bit more about the propulsion system. So, I want to get some books on that. I've got a basic idea.

Kevin: That's where the old books were fine; at the beginning, they just provided an explanation.

Todd: Yeah. I'm kind of unclear with some things about how it works, but what I decided to do is I'm going to learn very generally. I'm going to get a model of what a maglev is, and then say there are many different styles and things that you can do to change it.

All in all, the MIT group devoted significant attention to substantive talk, as is evident from the excerpts of their meetings. From their second meeting onward, the team concentrated much of their time on narrowing the topic down, defining the technical problem, brainstorming on possible solutions, and developing criteria to be 
met. The focus on substantive talk tended to diminish as the team progressed, yet, as the above example illustrates, it still permeated many discussions, even into the latter phases of the project.

Writing interaction also formed an integral part of the team's discussions, gradually taking up more time as the project progressed. Todd's early incorporation of "drafts" into the agenda of most team meetings helped ensure that sufficient attention was given to the writing process. Inevitably, discussions of drafts were often linked to a corresponding discussion of deadlines, as the following example indicates:

Todd: Okay. Individual drafts. Deadline reminder: I'll draw your attention to my beautiful [November] calendar.

Kevin: This calendar? Wow! Did you make this calendar?

Melissa: It's so pretty! And lifelike too!

Todd: Okay. And now you'll notice that we have nineteen days until the final report is due.

Kevin: Twenty.

Todd: Twenty was yesterday. Nineteen. Ten, twelve, fourteen, seventeen, yeah...nineteen. Nineteen days. Now what I propose is we look this over and try and come up with a workable plan to try and get this thing workable. How are we going to make sure that our final written report is all we claimed it to be in our [Oral Progress Report]?

Kevin: It will be.

The team's writing interactions included a version of the "think-aloud" protocol used by the writing centre at Simon Fraser University (Giltrow \& Valiquette, 1994; Giltrow, Cowan, Josephson, \& Valiquette, 1998), a protocol in which one member of a group reads a passage aloud and comments on it at the same time. The MIT team began this practice at their sixth meeting when Todd asked team members to prepare their own version of the problem statement to be included in the team proposal (Giltrow \& Valiquette, 1994; Giltrow, Cowan, Josephson, \& Valiquette, 1998). This section consists of two or three paragraphs that identify the specific technical problem under investigation and why it needs to be solved. As each team member articulated 
their perception of the problem, all the individuals on the team came to a shared understanding of the topic; at the same time, this strategy of verbally sharing perceptions stimulated further discussion.

The team used this strategy effectively in other phases of the collaborative project, including the abstract assignment. Because assignments such as these are organized so that all team members share the resulting grade, reading their sections aloud helps prepare team members to engage in the process of group revision and editing. Although group revision also takes place as each team member reviews the other's written work privately, discussing drafts as a group increases the team's overall familiarity with its intended writing style.

The following excerpt is from a meeting concerning the team's abstract assignment. At this point, each team member had prepared his/her own draft of the abstract, read each version aloud, and then, as a team, combined them into one. As they selected which sections to use from which author, they increasingly became concerned with such detailed issues as appropriate word choice and sentence length:

Todd: This is semi-redundant, this sentence, because it says "while being safer." Well, we already said it was safe above.

Melissa: How about we combine the two?

Kevin: Okay, so we take out "safer" there, and put in something about "requires less maintenance," and then we have the "safer" part down here.

Todd: Yeah, the safer part is better.

David: "In many ways."

Kevin: (Reading) "Maglev is superior in many ways to conventional transportation. It is a low-maintenance, economical, and environmental solution."

The team later used this strategy in their discussions of the final written report. In each meeting, team members orally summarized the content of their individual sections, and actually read sections out loud; they would also quietly review each other's drafts while making verbal comments concerning writing style and suggested revisions. Summarizing the content of each team member's section for the group was 
helpful in that it enabled team members to know the general layout of each other's section, reducing the likelihood of overlap between sections and leading to a firm grasp of the report's treatment of the topic.

As the due date approached for the final written report, the think-aloud strategy eventually gave way to more intense group revision and editing sessions. In these sessions, the team circulated drafts, and, while busy critiquing each other's work silently, team members would offer comments. By this point, team members had become increasingly familiar with the others' work, and they were even able to comment on components such as figures and tables in the report. As they exchanged and reviewed drafts with each other, issues of style began to take precedence. They scrutinized each other's work and looked especially for wordiness, the technical level of the language being used, appropriate use of active and passive voices, and tense.

In summary, the MIT group achieved a well-balanced approach to the forms of interaction identified by Van Pelt and Gillam (1991). Procedural, substantive, and writing talk were neither over represented nor under represented in their discussions. Of all the forms of interaction, though, social talk received the least attention, a noteworthy feature of this group. Although recognized as an important component in balanced interaction, social talk was kept to a minimum, probably due to the coordinating editor's frequent and consistent use of agendas throughout the project.

- Decision-Making:

There were several aspects of the group's decision-making process that were strongly linked to their overall successful collaborative style. The first was their timely and efficient approach to reaching decisions of all kinds, ranging from the procedural to the more substantive. For example, during their first in-class meeting, which lasted no more than a few minutes, team members had already tentatively decided on their roles; they formalized these roles in their second meeting two days later. By their third meeting, the team had selected the magnetic levitation system as their topic, and already reached agreement on the proposed internal deadlines Todd had presented to them. By their fifth meeting, team members had chosen which sections of the final written report they would author.

This timely attention to all the important matters relating to the project, such as topic and team assignments, was particularly crucial six weeks into the term, when Dwayne, the technical editor, withdrew from the course. The team dealt with this setback as soon as they became aware of it, incorporating it into the agenda. At that point, the team decided that his responsibilities should be re-assigned among team members. Kevin, the graphics editor, would assume the responsibility of compiling 
the bibliography as well as taking over Dwayne's assigned section of the report, while David would add technical editing for technical content and accuracy to his overall role as stylistic editor.

In the team interview, Todd commented that time constraints played a role in their decision-making process:

The other thing that was good about this was that we didn't have much time, so that means we had to make the decisions right there. As soon as you saw a problem, you had to fix it because you didn't have time to go back to it.... If we had all the time in the world, [we could say]: "We'll look at that later."

Secondly, the team's decision-making style was also anticipatory, with many decisions being made ahead of time whenever possible. The list of proposed internal deadlines concerning the team proposal, as well as the calendar of tasks and deadlines for the month of November, enabled the team to have assignments ready early. Two weeks before the due date for the final written report, for example, the team was meeting to discuss the introduction, conclusion, and recommendations, sections which many teams struggle with only days before the report is to be submitted. Unlike these less organized teams, the MIT's anticipatory approach enabled them to successfully plan their final oral report and even add two additional components-a multi-media presentation, and the use of magnets borrowed from the Physics department to help demonstrate the properties of the magnetic levitation system.

Once again, the use of an agenda may be seen as a contributing factor in achieving a successful decision-making style. An itemized agenda provides a natural structure to facilitate making decisions by reducing the likelihood of backtracking and procrastination. The structure implies that it is impossible to move on to the next item until the current item has been dealt with. This device, along with Todd's organizational skills and previous business experience, significantly reduced the opportunity for delaying decisions or wasting the team's limited time.

In addition to its timely and anticipatory approaches to decision-making, the third factor was the team's consensual nature. While team members were responsible for decisions regarding their own role and sections of the report, a number of decisions were made collectively, including the choice of topic, the technical problem and criteria, and the proposed solution to be investigated. Their approach to the abstract assignment illustrates their desire to reach consensus on matters of importance to the team. Because Dwayne, the technical editor, had just withdrawn from the course, and it had been his responsibility to recommend a magazine or journal article that the 
team could abstract for the assignment, the team decided to vote on the articles that each of them had brought to class and select the most popular one. In this way, the vote ensured that the result was agreeable to all.

In the team interview, Todd drew attention to the importance of making decisions as a group, as well as the need for individual initiative, specifically in regards to the writing process:

And then there were the general decisions that you make on your own. Like each person has a section, and they make their decisions to the best of their ability, and, where it affected the whole group, everybody raised up their points to the group so we could all make the decision. Like, my section was to explain how [maglev] worked, so I had questions that I had to have answered from the group, because what I did affected everyone else. So, in order to create a coherent report, I had to get a decision based on the group. But then there were a lot of decisions I had to make on my own.

Therefore, the group's decision-making approach was highly consultative in nature. On several occasions, Todd would make a decision on an issue that affected the team and then present it to them for their approval. This practice, in addition to a democratic approach to making decisions in a timely and anticipatory manner, acted to further cement the collaborative bond that the MIT group shared.

- Responsibility:

Allen et al. (1987) strongly emphasize the relationship between the decisions made as a document is evolving and the contribution of team members to the writing tasks that follow. In other words, a team member's sense of responsibility for a document should be seen as a natural by-product of their involvement in decision-making processes leading up to its creation. The decision-making processes that led to the MIT group's production of their final written report were efficient, anticipatory, and consensual, and these attributes, combined with the team's balanced approach to interactions, played a central role in the shared distribution of writing tasks that resulted.

The team's report, entitled "The Technical Viability of Maglev Systems in Canada," examined the feasibility of introducing a highspeed magnetic levitation system in Canada, and focused on cost, climate, and safety. A closer examination of the report reveals that there was a relatively equal division of labor among the four team members, with each person contributing roughly the same amount of written text. Additional sections, such as the introduction, conclusion, and abstract, were also equally distributed among team members. Even more significant, however, was the entire 
team's collaborative input into the revision phases of the project, especially when this mode of collaboration is compared with the imbalances shown by the Resource Management or the Aerospace teams, neither of which ever conducted a thorough team review of the drafts. The MIT team's project file showed that all team members had produced several drafts of their individual sections, and, as evidenced by the number of written comments on each draft, the team had carefully reviewed each other's work.

The MIT group was also more successful than these other teams in fulfilling the responsibilities associated with the report. For example, the professor praised the recorder highly for her thorough and detailed notes of team meetings. Todd even ensured that copies of agendas from all team meetings were enclosed along with the minutes. The professor also commended the team for the report's overall layout as well as its project file, both of which were the coordinating editor's responsibility. The other two team members, the stylistic editor and the graphics editor, were less successful in fulfilling their roles. While generally readable, and certainly sufficient attention had been paid to the number of drafts and revisions, the report nonetheless contained problems with tone and coherence, while the report's graphics were not particularly well-documented or well-integrated into the text of the report.

The greatest weakness associated with the report, however, concerned its lack of a specific technical focus; that is, because it identified a technical problem in only the most general terms, the "why" of the report was unclear. So, while it explained magnetic levitation technology well enough and examined it according to such criteria as cost, climate, and safety, the report remained vague as to what this technology would replace and for what reasons. The report was also unable to situate the analysis beyond the general jurisdiction of "Canada" to a more specific locale or to a specific application.

Although the team as a whole should have paid attention to these issues in the formulation of their topic, it is usually the technical editor's responsibility to ensure the technical focus of the document is clearly stated. Since the team's technical editor had withdrawn from the course, the team divided his responsibilities among themselves, and such action may have contributed to this weakness in the report. In this regard, an analysis of the team's meeting transcripts is revealing. While many of their discussions were substantive in scope, with a focus on the workings of maglev technology, neither the specific technical context for the discussion nor the specific technical problems to be addressed were fully discussed. The professor's comments on the evaluation sheet support this finding: "A feasibility study must define the problem to be solved, the technical issues to be addressed..... And what factors about a 
specific locale will determine feasibility (e.g. terrain, population, size) ?"All in all, the report produced by the MIT team was a solid discussion of technology, but it was too general in its treatment of a specific engineering problem.

\section{Summary}

Two of the teams we studied-the Resource Management team and the Aerospace team - had great difficulty in establishing these three collaborative components of interaction, decision-making, and responsibility, and the result was a lower quality report. For example, in terms of their interactions, both teams focused too much attention on procedural talk; that is, talk that determined how the team would proceed with such things as arranging meetings and assigning tasks to individual members (Appendix 2). Often, too, their conversations focused on outside activities or personal matters that had little to do with either the team dynamic or the project (Van Pelt and Gillam, 1991). So, instead of discussing writing and revision, or focusing on substantive issues concerning the project, talk that would have helped them increase their productivity and develop more completely as a team, these teams indulged in group talk that tended to stall their efforts and weaken their efficacy. As well, their patterns of decision-making and responsibility were remarkably similar. Frequently, they delayed their decision-making, and, at times, had a last-minute approach that was typically under the control of only one or two team members. Finally, their responsibilities towards the team and the project were ultimately imbalanced, and, in most cases, their group roles were abandoned.

Thus, we found that these less successful teams shared some common attributes. Altogether, these similar collaborative styles can be traced back to their casual approach to meetings, including their length, frequency, and structure, and to their failure to attend to the importance of attendance, punctuality, and familiarity with the course handbook. The final written report produced by these two teams was a reflection of the difficulties encountered, suffering as it did from technical, organizational, and stylistic problems. More damaging, though, was the negative influence of their team leaders.

In contrast, the MIT team was successful in their mode of collaboration. Over the course of the project, they consistently demonstrated a strong approach to the collaborative process. As shown in Figure 3, their mode of collaboration combined balanced interactions with timely, consensual decision-making, and shared responsibility.

This collaborative style was strongly influenced by the distinctive leadership of Todd, the team's coordinating editor, who ensured that the team always focused on tasks. At the same time, he used a highly consultative approach to help preserve the 


\section{INTERACTION}

Committed, on-task and professional approach to meetings

Balance between substantive, procedural and writing talk with

less time spent on social talk

Focused and agenda-driven meetings with frequent use of

feedback and "pulse checks"

\section{DECISION-MAKING \\ Timely, efficient, and at times anticipatory \\ Consensual, democratic \\ Consultative}

Team roles fulfilled

\section{RESPONSIBILITY}

Balanced, even workload with clearly defined boundaries

Report completed ahead of schedule

Higher quality report (from technical, organizational and stylistic standpoints)

\section{Figure 3: The collaborative Profile of the Mechanical and Industrial/ Transportation (MIT) Team.}

team's emotional well-being. It was this concern for the personal side of the collaborative effort that played such a strong role in the team's overall success and contributed to its ability to produce a higher quality document than did either the Resource Management team or the Aerospace team, whose leaders were far less effectual in promoting or achieving the intended outcome.

The data from this larger study on collaboration highlight the linkage between effective leadership and successful team outcomes. As the demand for team-based projects in the Engineering classroom continues to increase, in part because of the advice given by the Canadian Engineering Accreditation Board (CEAB), there will be an ongoing need to conduct research into effective teams. Leadership, as seen here, is clearly a major component in the collaborative process. More qualitative studies that use an in-depth and detailed approach to investigating leadership will add a muchneeded dimension to this important topic. 


\section{Appendix 1:}

\section{TEAM ROLES IN BRIEF}

Graphics Editor: responsible for all graphics inthe team's written and oral work, including integration into the text, layout and format, documentation; drafts the team's work schedule.

Stylistic Editor: responsible forsetting deadlines for the team's drafts, and setting out writing and revising strategies for the team's individual and joint sessions.

Technical Editor: responsible for the report's technical focus, as well as establishing strategies for research and documentation.

Recorder: responsible for maintaining a complete record of the team's meetings and decisions, including anything to do with assigned tasks or deadlines.

Coordinating Editor: responsible for the layout and format of all team assignments, as well as devising a meeting schedule and agendas, chairing team meetings and ensuring participation.

Source: Parker, A., Strong, C., \& Ingram, S. (1997-1998; 1998-1999). Technical communication handbook (pp. 43-44). Winnipeg, MB: Department of Electrical and Computer Engineering, University of Manitoba. 


\section{Appendix 2: \\ TYPES OF GROUP “TALK”}

procedural talk - necessary part of each group session at the beginnning

- concerns the division of labour, setting goals, ordering priorities, arranging meetings

- becomes less critical as project and team evolve

social talk - team-building talk, since it helps to cement the team's collaborative bond

- chatter about outside activities, often friendly bantering and "joking around," but often personal

writing talk - discussion on the writing process itself, including matters of style as well as co-authoring, commenting on and revising team drafts

- usually a part of most group sessions, but becomes increasingly more important and more frequent as the project progresses

substantive talk - subject-related,including brainstorming and sharing views about the topic itself, explaining processes, asking questions and solving problems

- should involve all team members (otherwise, the team risks splintering into sub-groups or becoming a loose collection of individuals)

- becomes increasingly the focus for the group as the work progresses (but can limit participation if engaged in too soon, such as before the brainstorming or more general discussions are complete)

- often interspersed with writing talk

Source: Van Pelt, W. \& Gillam, A. (1991). Peer collaboration and the computerassisted classroom: Bridging the gap between academiaand the workplace. In M. Lay \& W. Karis (Eds.), Collaborative writing in industry: Investigations in theory and practice ( pp. 170-205). New York: Baywood Publishing Co. 


\section{REFERENCES}

Allen, N., Atkinson, D., Morgan, M., Moore, T., \& Snow, C. (1987). What experienced collaborators say about collaborative writing. Journal of Business and Technical Communication, 1 (2), pp. 70-90.

Giltrow, J. \& Valiquette, M. (1994). Genres and knowledge: Students writing in the disciplines. In A. Freedman and P. Medway (Eds), Teaching and learning genre (pp. 47-62). Heinemann.

Giltrow, J., Cowan, A., Josephson, S. \& Valiquette, M. (1998). Feedback: Its uses and reliability. Paper presented at the annual conference of the Canadian Association of Teachers of Technical Writing, Canadian Congress of the Social Sciences and Humanities, Ottawa, Ontario.

Herrick, J. W. (1999). "And then she said": Office stories and what they tell us about gender in the workplace. Journal of Business and Technical Communication, 13 (3), pp. 274-296.

Ingram, S. \& Parker, A. (2002a, January). Gender and modes of collaboration in an engineering classroom: A profile of two women on student teams. Journal of Business and Technical Communication, 16 (1), pp. 33-68.

Ingram, S. \& Parker, A. (2002b). Gender and collaboration: Communication styles in the engineering classroom. Halifax: Fernwood Publishing.

Ingram, S. \& Parker, A. (2002c, March). The influence of gender on collaborative projects in an Engineering classroom. IEEE Transactions of Professional Communication, 45 (1), pp. 7- 20.

Johns, G. (1996). Organizational behavior: Understanding and managing life at work. 3rd Edition. New York: Harper Collins.

Katzenbach, J.R. \& Smith, D.K. (1993). The wisdom of teams: Creating the highperformance organization. Boston, MA: Harvard Business School Press.

MacIver, D. \& Epstein, J. (1991). Responsive practices in the middle grades: Teacher teams, advisory groups, remedial instruction and school transition programs. American Journal of Education, 99 (4), pp. 587 - 622.

McIlwee, J.S. \& Robinson, J.G. (1992). Women in engineering: Gender, power and workplace culture. Albany, NY: SUNY Press. 
Morgan, M. (1994). Women as emergent leaders in student collaborative writing groups. Journal of Advanced Composition, 14 (1), 203-219.

Padgett, D. (1998). Qualitative methods in social work and research: Challenges and rewards. Thousand Oaks, CA: Sage.

Parker, A., Strong, C., \& Ingram, S. (1997-1998; 1998-1999). Technical communication handbook (pp. 43-44). Winnipeg, MB: Department of Electrical and Computer Engineering, University of Manitoba.

Stewart, G. \& Manz, C. (1995). Leadership for self-managing work teams: A typology and integrative model. Human Relations, 48 (7), pp. 747-77o.

Van Pelt, W. \& Gillam, A. (1991). Peer collaboration and the computer-assisted classroom: Bridging the gap between academia and the workplace. In M. Lay and W. Karis (Eds.), Collaborative writing in industry: Investigations in theory and practice (pp. 170-205). New York: Baywood Publishing Co.

Winter, J.K., Neal, J.C., \& Waner, K.K. (2001). How male, female, and mixed-gender groups regard interaction and leadership differences in the business communication course. Business Communication Quarterly, 64 (3), pp. 43-58. 